ISSN 1112-9867

Available online at $\quad$ http://www.jfas.info

\title{
FIFTEEN-COMPONENT EIGHTH-LEVEL ALGORITHM OF COMPETITION AND INDUSTRIAL POLICIES HARMONIZATION
}

\author{
E. E. Zainutdinova
}

Kazan Federal University

Published online: 08 August 2017

\begin{abstract}
The article offers a new approach and mechanism for managing of competitive advantages at the mesolevel by harmonization the competition and industrial policies.

The structural model of the fifteen-component eight-level concept of competition and industrial policies harmonization is presented, on the basis of which the algorithm of competition and industrial policies harmonization based on labor productivity is made.By this algorithm, as a result of combined comparative assessment on the synchronous indicators of labor productivity, eight standard strategies and also recommendations for the formation of new strategies are developed.

New groups of indicators are presented - «synchronous indicators» of competition and industrial policies, allowing to monitor the simultaneous implementation of both policies, «specific indicators» that can only be used to assessment competition or exclusively industrial policy and «combined indicators» of competition and industrial policies, which are become by uniting the above-stated specific indicators. The method of this indicators calculation is developed.
\end{abstract}

Keywords: competitiveness, competition policy, industrial policy, harmonization, tools, performance indicators, synchronization, labor productivity.

\section{INTRODUCTION}

The world experience shows, that one of the main factors of economic stability is the providing of high competitiveness at the mesolevel, which unites territorial and branch

Author Correspondence, e-mail: elzaye1@rambler.ru

doi: http://dx.doi.org/10.4314/jfas.v9i2s.68 
elements of development[1-4].At the present time in economic science, separate methodological approaches on managing the basic components of competition at the mesolevel have been formed [5-7].However, as our researches show, taking into account economic and geographical diversity, the heterogeneous nature of the regional systems development, it is necessary to seriously adapt the existing and develop new methodological foundations for managing of competitive advantages elements, taking into account differentiation, cooperate and expand the possibilities of using industrial policy tools.

In this regard, improving the competitive advantages management of territories and types of economic activity on the basis of competition and industrial policies harmonization is the important scientific and applied task of economic science.

The essence of the proposed approach consists in the comparative analysis of the most important parameters of territories and types of economic activity development and diagnosing the main problems with preparation of the most reasonable offers for raising the policies effectiveness of territories and industries, taking into account the available positive experience in solving same or similar problems.

The concept of competition and industrial policies harmonization on the basis of integrated system of performance indicators, allowing forming recommendations on differentiated application of the relevant tools taking into account the features of regions is the basis for the offered approach.

The offered approach is based on the concept of competition and industrial policies harmonization on the basis of integrated system of performance indicators, which allows formulating recommendations on the differentiated application of the relevant tools taking into account the characteristics of the regions.

\section{METHOD}

The general scientific methods of theoretical level (generalization, analysis, synthesis, induction, deduction, etc.), private methods of economic sciences (analogy, interpretation, formalization, etc.) and specially developed specific methods were applied in carrying out researches. The researches were based on results of the competitiveness comparative analysis of the Russian Federation most economically developed regions in the sphere of whole-milk products production on performance indicators executed on the basis of retrospective information of Federal State Statistics Service. 


\section{RESULTS}

As a result of decomposition of tasks, tools and performance indicators of competition and industrial policies, we developed the fifteen-component eight-level concept of their harmonious and synchronous conducting, the structural model of which is presented in Figure $1[6-7]$.

The first level includes two components, which define the main tasks of both policies. The main tasks of competition policy - are the formation and maintenance of equal conditions for all market participants, activity development, regulation of business activity and implementation of antimonopoly control. The main tasks of industrial policy - are the creation and maintenance of special conditions for priority sectors of economy and regions at the expense of public funds to enhance their competitive advantages and development dynamism.

The second level consists of the third and fourth components for systematization, classification and ranking of tools, acting as a means of achieving the tasks of two policies.

The tools of these policies are many. Each of them has a different spectrum and impact level on the efficiency of the policies in question. On the structural model of the offered concept (Figure 1), the tools of competition policy are denoted as CPT 1, CPT 2, ..., CPT F, and industrial policy as IPT 1; IPT 2; ...; IPT G.

The sequence numbers of tools indicate a place in the ranked row on degree of impact efficiency on competitiveness indicators. It should be noted, that the efficiency degree of the same tool may vary depending on situations (SIT), strategies (ST), region (REG), industry (IND) and type of economic activity (TEA):

$$
E_{C P T(I P T)}=F(S I T ; S T ; R E G ; I N D ; T E A) .(1)
$$

The efficiency carrying out of two approaches is assessed by a set of indicators.

The third level - is the systematization, classification and formation of competition and industrial policies indicators [8]. Despite the available significant difference in the ideology and principles of two approaches, the analysis, systematization and grouping of the tools existing in them allows to form three conditional groups of indicators, that make up the fifth, sixth and seventh components. 


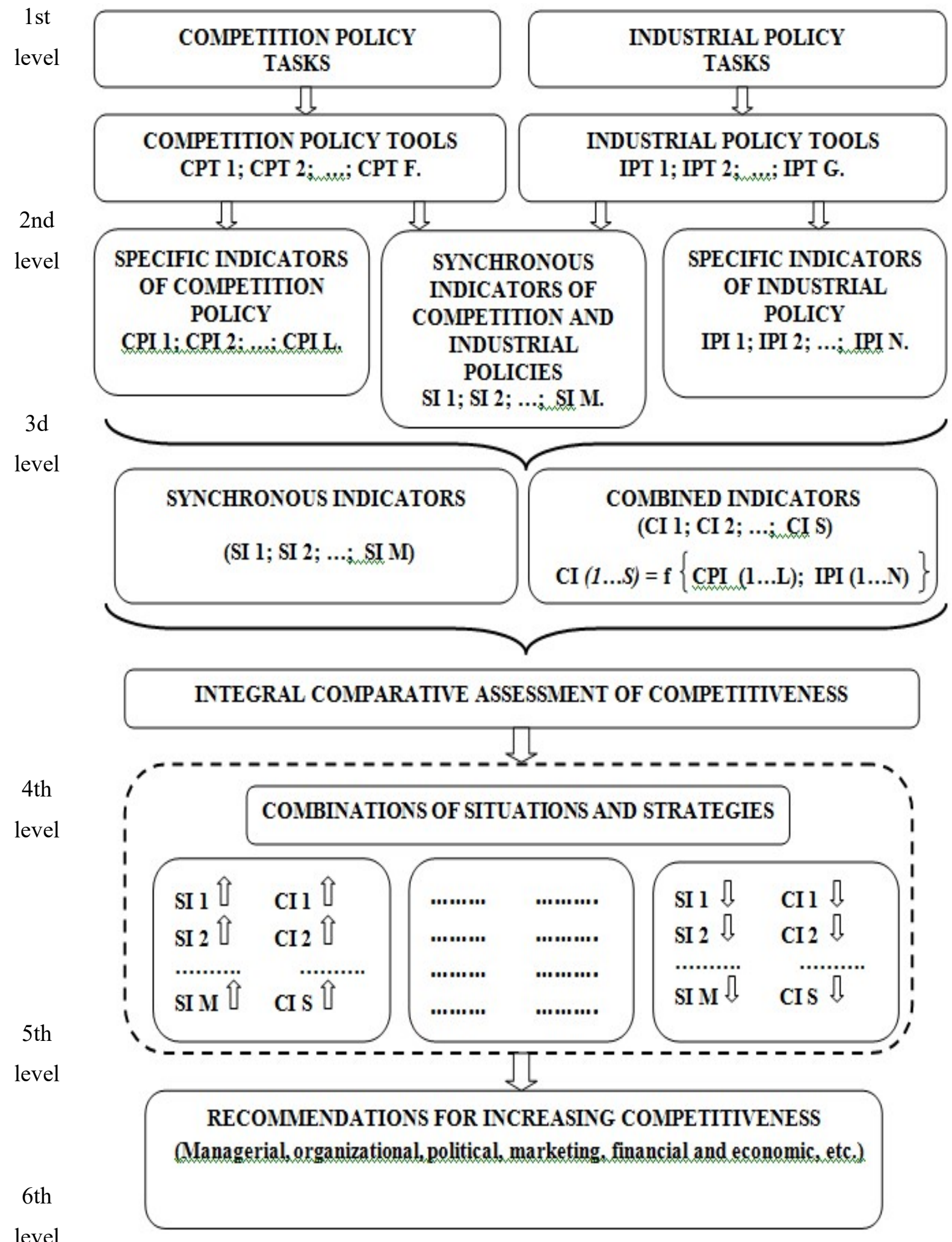

Fig.1. Structural model of the fifteen-component eight-level concept of competition and industrial policies harmonization 
The group of specific indicators of competition policy (in Figure 1 are denoted as CPI 1, CPI 2 ,..., CPI L) characterizes the carrying out efficiency and provides monitoring only of competition policy.

The group of specific indicators of industrial policy (in Figure 1 are denoted as IPI 1, IPI 2,..., IPIN) characterizes the carrying out efficiency and provides monitoring exclusively of industrial policy.

The system of synchronous indicators (in Figure 1 are denoted as SI 1, SI 2, .., SI M) can be used simultaneously for efficiency characteristic and competition policy, and industrial policy, and monitor their carrying out and synchronization.

The fourth level is formed by the eighth and ninth components, representing indicators for efficiency assessing of harmonious carrying out of two policies. We proposed new synchronous (discussed above) and combined indicators.

The system of combined indicators (in figure 1 they are denoted as CI 1, CI 2, ..., CI S), in contrast to synchronous ones, which in nature have a general character, is combined of the specific indicators of two policies. They, along with the characteristic of efficiency of both competitive and industrial policies, allow us to assess the degree of integration and effectiveness of their tools interaction.

The sequence number of each indicator specifies its place in the ranked row by completeness of the assessment of the efficiency degree and the monitoring possibility. They allow obtaining conditions for the harmonious development of both competition policy, and industrial policy and, on this basis, to construct a common integral assessment of efficiency.

The tenth component (the fifth level) is an integrated comparative assessment of competitiveness by synchronous and combined indicators, as a result of which determines combinations of possible situations and strategies (the eleventh component, the sixth level).

The next twelfth, thirteenth and fourteenth components of the seventh level represent three groups of possible situations combinations that determine the strategy for increasing competitiveness.

The fifteenth component of the final eighth level represents the development of concrete practical managerial, organizational, political, marketing, financial-economic and other recommendations for improving competitiveness.

At realization of the offered approach, it is possible to use different synchronous and (or) combined indicators, depending on the goals and tasks of a particular economic entity, functioning in a concrete situation. For the practical application of the offered synchronous and combined performance indicators of competition policy (CP) and industrial policy 
(IP)harmonization, we developed a method of their calculation, the algorithm of which is presented in Figure 2.

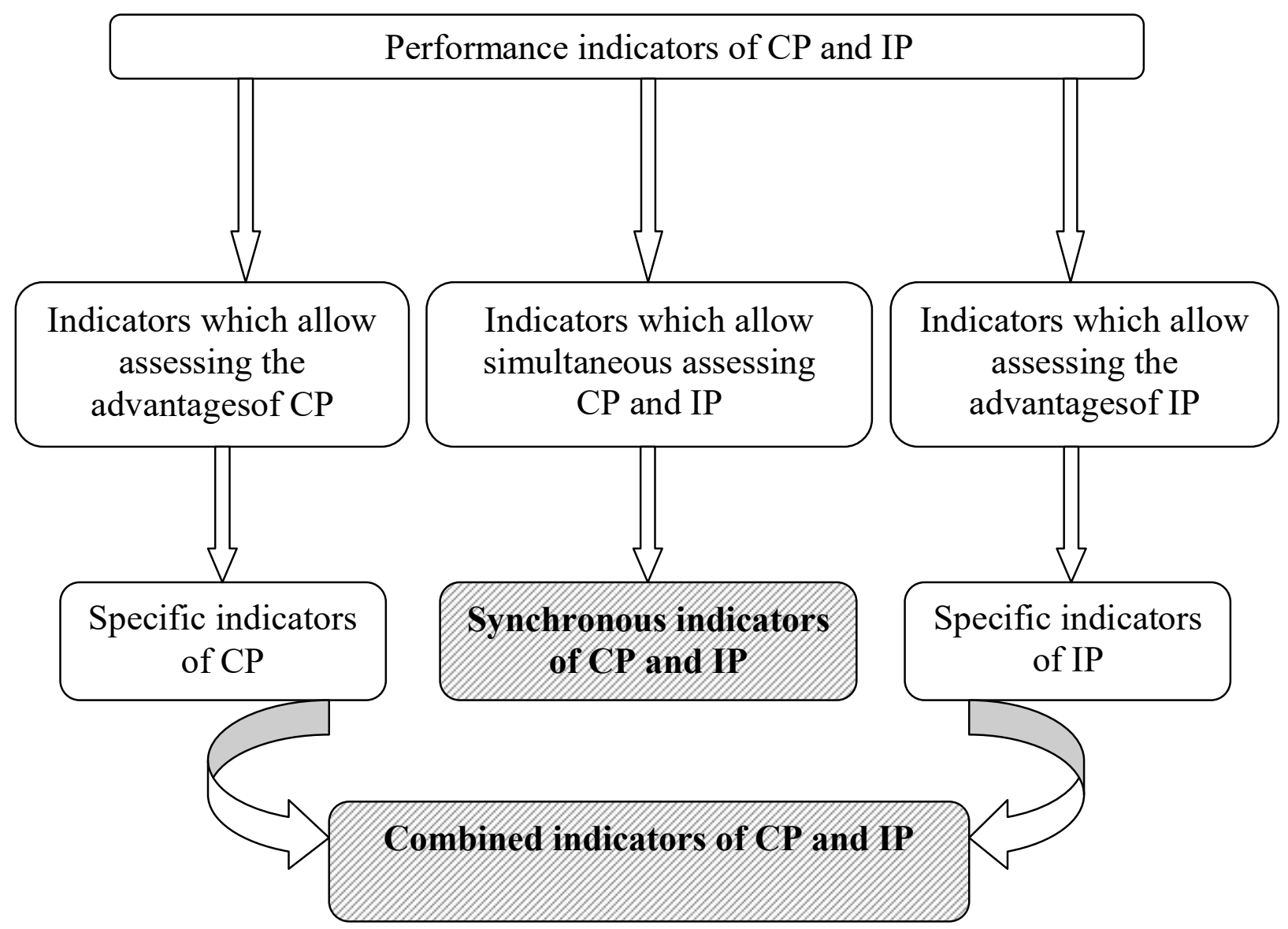

Fig.2. Algorithm of synchronous and combined indicators calculation method

The practical applicability of the offered approach, in our opinion, can be shown on the example of labor productivity, which is the most effective, capacious and simple indicator[9]. As a result of the detailed decomposition and subsequent creative synthesis of synchronous indicators, the following of them were selected, which allow assessing both these major processes, the calculation of these indicators according to the developed algorithm we propose as follows:

1. The ratio of organizations turnover in monetary terms to the number of man-hours worked (PM, ruble/man-hour):

$$
\mathrm{PM}=\mathrm{OTMT} / \mathrm{NMHW}
$$

2. The ratio of volume of shipped products in kind to the number of man-hours worked (PK, tons/man-hour):

$$
\mathrm{PK}=\mathrm{VSPK} / \mathrm{NMHW}
$$


3. The ratio of volume of shipped products in-kind to the average number of employees (PE, tons/man):

$\mathrm{PE}=\mathrm{VSPK} / \mathrm{ANE}$,

where OTMT - organizations turnover in monetary terms, ruble;

NMHW - number of man-hours worked, man-hours;

VSPK - volume of shipped products in kind, tons;

ANE - average number of employees, man. where

On the basis of the eight-level fifteen-component concept (see Figure 1), the algorithm of competition and industrial policies harmonization based on labor productivity indicators is made (Figure 3). By this algorithm, as a result of combined comparative evaluation on the synchronous indicators of labor productivity, eight standard strategies are developed[10].

The first strategy. The ideal situation. Increasing of all indicators demonstrates the effective management of competitive advantages and dynamic development, outstripping competitors. In this option, it is offered to focus more on technological leadership by introducing innovations, reducing costs with maintaining and (or) increasing the production, the range and expanding the sales market, mastering new raw material markets, and also gradually absorbing competitors. 


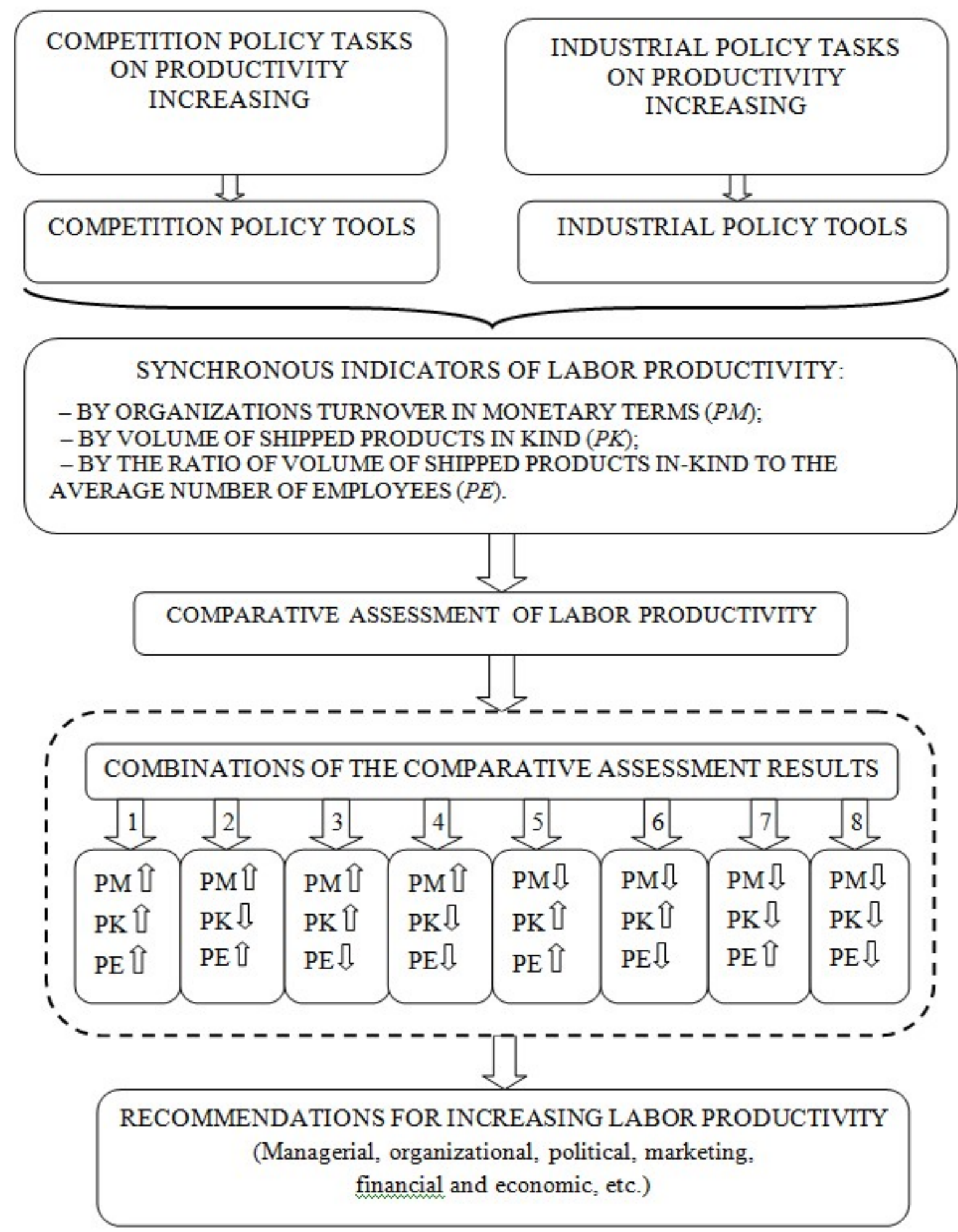

Fig.3. Structural scheme of harmonization of competition and industrial policies indicators on the basis of synchronous indicators 
The second strategy. Labor productivity in monetary terms and by employees increase, in kind decreases. It, most likely, evidences about irrational use of working time, i.e. there is a peculiar over expenditure of working time for the production of a unit of output. It turns out, that labor productivity in doing so is provided generally due to the high price of manufactured products. Therefore, as a model strategy, it is proposed to carry out a set of measures for assessment, filtration and introduction of innovative technologies, technical re-equipment and improvement of production organization.

The third strategy. Labor productivity in monetary terms and in kind grow. By the employees of organizations falls. In this case, the advantages are provided mainly due to the price factor in a compartment with the overall intensification of labor. Development happens due to increase in number of employees with a small fund of working time, that is, there is an excess of labor resources. Possible reasons of this situation are under loading and incomplete development of production capacities, a narrow qualification of workers, which does not allow them to be used effectively. As a strategy for increasing competitiveness, it is recommended the technical and technological re-equipment of a part of production facilities for the production of a new market-demanding, import-substituting product range with simultaneous re-qualification and redistribution of manpower. Accordingly, it is necessary to make amendments to marketing, sales, raw strategies, providing for access to lower price segments. Along with this, it is possible to consider an increase in shift work, outsourcing application, where internal labor reserves are used problematically. As a last resort reduction of low-skilled workers may be offered.

The fourth strategy. Productivity in monetary terms increases. Labor productivity in kindandby average number of employees fall. At this option, the increase in productivity is ensured only at the expense of price factor that speaks about competitive instability, or about temporary conjuncture shifts. The intensity of labor is at a low level, the surplus of manpower along with the high expenses of working hours is demonstrated. In this situation it is recommended to introduce of innovative technologies, technical modernization, skill upgrading and diversification of manpower oriented to production high-quality and cheap new products demanded by the market. Along with this, it is necessary to improve the organizational and management structure, introduction of new marketing approaches that ensure the expansion of the sales market.

The fifth strategy. Labor productivity in kind and by employees grow. In monetary terms falls. Such situation shows, despite the high efficiency of manpower use, production capacities allow producing only high-cost products, which does not allow raising prices and 
expanding sales markets. For this option, as recommendations, it is offered to carry out technical modernization with the development of perspective production technologies with low prime cost of a wide set of new qualitative products for different consumer levels of life. At the same time, the reorientation of production and expansion of the target market should be accompanied with carrying out adequate price and marketing policy.

The sixth strategy. Productivity in kind increases. Labor productivity on cost indicator and quantity of manpower decrease. The increase in productivity here is ensured by increasing the number of employees with a small fund of working time, that is, there is underutilization of labor resources and (or) an excess of manpower. A factor reducing competitiveness is the low price for manufactured products. A set of measures for the technological re-equipment of production to increase the range and reduce the costs of the products with simultaneous retraining and diversification of labor resources is recommended. Accordingly, it is necessary to revise the marketing and pricing policies, with the aim of bringing products to a higher price segment of market and increasing the sales market.

The seventh strategy. Labor productivity by average number of employees increases, in monetary terms and in kind fall. Competitiveness is supported by intensive use of manpower. There is a large workload of labor here is obvious. The decline in labor productivity is influenced by the price factor, that is, the low price for manufactured products. As a strategy for increasing competitiveness, it is proposed to conduct a complex of labor-saving measures for technical re-equipment, rationalization the organization of production, improving marketing, conquering new niches with a higher price segment.

The eighth strategy. Decrease in all indicators of productivity in this option gives grounds to assert that there is a systemic problem in the production and enterprises are noncompetitive. It is necessary to update the management and develop a new business strategy that includes technological measures, technical re-equipment, efficient use of labor resources, development of the concept of sales and marketing, and organization of production.

\section{SUMMARY}

Despite the contradictory nature of tasks of the competition and industrial policies, the analysis, systematization and grouping of their (CPT and IPT) tools allowed to develop system of indicators that allow us to evaluate the relevant measures and optimize them.

There is a new system of synchronous and combined indicators of the competition and industrial policies efficiency. Synchronous indicators correspond to common tasks, and 
combined - to specific tasks having common interest to ensure the sustainability of economic growth and growth the well-being of population.

Synchronous and combined indicators allow to carry outan integrated comparative assessment of competitiveness on possible scenarios of efficiency indicators ratio and to formulate recommendations by differentiated application of competition and industrial policies tools, taking into account economic, geographical diversity, and the heterogeneous nature of regional systems development.

\section{CONCLUSION}

According to the developed structural model of the fifteen-component eight-level concept of competition and industrial policies harmonization, the algorithm of competition and industrial policies harmonization based on labor productivity is made.By this algorithm, as a result of combined comparative evaluation on the synchronous indicators of labor productivity, eight standard strategies and also recommendations for the formation of new strategies are developed.

\section{ACKNOWLEDGEMENTS}

The work is performed according to the Russian Government Program of Competitive Growth of Kazan Federal University.

\section{REFERENCES}

1. Chamberlin E. H. Measuring the Degree of Monopoly and Competition // Monopoly and Competition and Their Regulation. E. H. Chamberlin, ed. L.: Oxford University Press, 1954.

2. Blaug M. Economic theory in retrospect (5th ed.). - Cambridge New York: Cambridge University Press, 1997

3. Porter M. Competitive Strategy: Techniques for Analyzing Industries and Competitors. New York: The Free Press, 1998. - 397 p.

4. Hayek F. The sense of competition // Modern competition, 2009. - №3. - P. 18-27.

5. Safiullin M. R., Safiullin A. R. Regional competitive advantages (on the example of the Republic of Tatarstan). Kazan: Kazan University, 2011. 716.

6. Elshin L. A. Evaluation of the relationship between the business activity of the region and the economic activity of industrial sectors of the economy (on the example of the Republic of Tatarstan) // Science and education: future development. Cheboksary, 2017.

7. Econometric methods for evaluating of open national innovative systems // Kudryavtseva 
S.S., Shinkevich A.I., Pavlova A.V., (...), Doronina F.K., Ishmuradova I.I. // International Journal of Economics and Financial Issues 6 (2), 2016. - pp. 640-645

8. Zainutdinova E. E. Common performance indicators of competition and industrial policies // Izvestiya of the St. Petersburg State Agrarian University. - St. Petersburg, 2016. - 45. - P. 222-226.

9. Safiullin M. R. Safiullin L. N. Competitiveness of Russia: look of the World Economic Forum (review article) // Electronic economic vestnik of Tatarstan. - Kazan, 2012. - 2-3. - P. 27-41.

10. Zainutdinova E. E. Development of recommendations for specification of competition and industrial policies strategy with the help of research of labor productivity indicators // Izvestiya of the St. Petersburg State Economic University. - St. Petersburg, 2015. - 6. - P. $110-114$.

\section{How to cite this article:}

Zainutdinova E E. Fifteen-component eighth-level algorithm of competition and industrial policies harmonization. J. Fundam. Appl. Sci., 2017, 9(2S), 919-930. 